\title{
A unifying framework for the study of population aging
}

\author{
Warren Sanderson and Sergei Scherbov*
}

\begin{abstract}
Aging is a complex, multifaceted phenomenon. In this paper, we provide an integrative approach that allows for the study of numerous dimensions of aging within a unified framework. The framework is based on the translation of quantitative measures of people's characteristics into a new form of age measure, called "alpha-age." Two individuals who have the same alpha-age have the same level of the characteristic under consideration. Alpha-ages are easy to understand and analyze because they are measured in years, just like chronological age. Indeed, chronological age is just an alpha-age for which the characteristic is the number of years the person has lived. An advantage of using the alpha-age measure is that it allows for the translation of different characteristics into years of age. Expressing multiple characteristics that are otherwise difficult to compare using a common metric makes it possible to conduct comparative analyses that previously were not feasible. We demonstrate the integrative power of alpha-ages through a set of examples in which we present alpha-ages based on remaining life expectancy, fiveyear survival rates (a rough objective indicator of health), self-reported health, and hand grip strength. We also show how alpha-ages can be used to compute old-age thresholds that vary over time and place, and how alpha-ages can be used to compute intergenerationally equitable normal pension ages. By allowing for the consistent quantitative measurement of multiple aspects of aging, the integrative approach presented here provides us with new insights into the process of population aging.
\end{abstract}

\footnotetext{
* Warren Sanderson (corresponding author), World Population Program, International Institute of Applied Systems Analysis, Austria; and Department of Economics, Stony Brook University, USA Email: warren.sanderson@stonybrook.edu

Sergei Scherbov, World Population Program, International Institute of Applied Systems Analysis, Austria; Vienna Institute of Demography/Austrian Academy of Science, Austria; and Russian Presidential Academy of National Economy and Public Administration, Russian Federation
} 


\section{Introduction}

A new approach to the study of population aging is needed. The current literature has two main branches. The first branch is based on the conventional aging measures produced by the United Nations that distinguish people solely on the basis of their chronological age (United Nations 2013a). A frequently used measure of population aging is the proportion of the population who are classified as "old." Various UN measures categorize people as old when they reach their $60^{\text {th }}$ or their $65^{\text {th }}$ birthday. But shouldn't a 65-year-old with a remaining life expectancy of five years be distinguished from a 65-year-old with a remaining life expectancy of 25 years in the study of population aging?

The second branch is a set of disconnected studies of the differing characteristics of people. For example, cognitive functioning is studied using one set of measures (Weber et al. 2014; Skirbekk, Loichinger and Weber 2012; Schneeweis, Skirbekk and Winter-Ebmer 2014; Stoet and Geary 2013; Flynn 1987), and physical functioning is studied using another set of measures (Leong et al. 2015; Sanderson and Scherbov 2014; Al Snih et al. 2004; Habibi et al. 2013; Innes 1999). It might be possible to determine that both cognitive and physical functioning improved over time in a particular country, but even in that case there would be no natural way to compare these changes.

Neither of these two branches of the literature is fully satisfactory because aging is a complex, multifaceted phenomenon in which the changes in the characteristics of people are interrelated. The conventional approach relies on aggregate measures that ignore the differences in the characteristics of people over both time and place, and thus yields results that are incomplete and biased. While studies of particular characteristics are of interest in their own contexts, they cannot be readily analyzed together.

In 2013, we provided the formal structure for a new approach to the study of population aging that united the two branches (Sanderson and Scherbov 2013). We called our methodology "the characteristics approach" to the study of population aging; and although we first gave the methodology this name in 2013, we had used it informally in our previous studies as well (Sanderson and Scherbov 2005, 2007; Lutz, Sanderson and Scherbov 2008; Sanderson and Scherbov 2008a, 2008b, 2010). The characteristics approach is based on the translation of quantitative measures of people's characteristics into a new form of age measure that we call "alpha-age." In this paper, we provide a series of examples based on our previous research that show in detail the ability of the characteristics approach to provide a unifying framework within which new aggregate measures of population aging can be produced, and specific aspects of this topic can be studied. By allowing for the consistent quantitative measurement of multiple aspects of aging, the characteristics approach can generate new insights that are relevant for both scientific study and policy formulation.

The paper is organized as follows. In Section 2, we show how alpha-ages are constructed, without referring to any particular characteristic. In the following four 
sections, we provide detailed examples of the usefulness of alpha-ages. In Section 3, we discuss alpha-ages using remaining life expectancy as the characteristic of interest. We also present a new tool for visualizing patterns of alpha-age changes. In Section 4, we discuss the use of alpha-ages for the study of disabilities and health. In Section 5, we discuss how alpha-ages can be used in conjunction with biomarkers and other survey-based measures. In Section 6, we describe how alpha-ages can be used to determine intergenerationally equitable normal pension ages. In Section 7, we discuss the relationships between alpha-ages and other age measures, such as thanatological ages and anticipatory ages. In Section 8, we outline some technical considerations. In Section 9, we offer some concluding thoughts.

\section{The unifying framework}

Our framework (Sanderson and Scherbov 2013) takes into account that the agespecific characteristics of people that are relevant for the study of population aging change over time, differ from place to place, and vary across population subgroups. Among the many age-specific characteristics that could be considered are remaining life expectancy, the probability of dying in the next few years, the proportion of the adult lifetime spent after a specific age, healthy life expectancy, the proportion of people with severe activity limitations, measures of cognitive functioning, measures based on biomarkers, and subjective life expectancy. The chief advantage of our framework is that it allows for the analysis of all of these characteristics within a single unified structure.

While chronological age is one characteristic of an individual, on its own it is insufficient to represent the multifaceted phenomenon of aging. For example, a group of 65-year-olds with a college education may be much healthier, have fewer disabilities, and have a longer remaining life expectancy than a group of 65-yearolds with less than an upper secondary education. The chronological ages of these two groups are the same, but their characteristics are likely to be quite different. To gain a deeper understanding of aging, it is crucial that we move beyond the use of measures that are based solely on chronological age by developing tools that take into account the characteristics of individuals. The approach we have developed involves translating characteristics into alpha-ages.

The basic building blocks of the unifying framework are a set of schedules of the age-specific characteristics of people indexed by $r, C_{r}(a)$. The schedule $r$ can refer to different years, different places, different genders, or different subgroups of the population; or to any other feature that distinguishes groups of people.

$$
k_{r}(a)=C_{r}(a),
$$

where $k_{r}(a)$ is the level of the characteristic of individuals at chronological age $a$ in characteristic schedule $r$.

If $C_{r}(a)$ is continuous and monotonic in age over the relevant range, holding $r$ fixed, it can be inverted to obtain an age associated with a characteristic level. 
We denote this inverse, which maps characteristics onto chronological ages, by $C_{r}^{-1}(k)$. Clearly,

$$
a=C_{r}^{-1}\left(k_{r}(a)\right) .
$$

The computation of alpha-ages generally requires two characteristic schedules, which are denoted by $r$ and $s$. We often treat the characteristic schedule $s$ as a fixed standard, and hold it constant as $r$ varies. The alpha-age corresponding to chronological age $a$ is the chronological age in schedule $s$ at which the level of the characteristic is the same as it is at chronological age $a$ in schedule $r$. Formally,

$$
\alpha=C_{s}^{-1}\left(C_{r}(a)\right) .
$$

Using Table 1, we provide a step-by-step example of how an alpha-age is calculated.

The steps proceed moving from left to right in Table 1. First, a chronological age of interest is chosen. In the left-most column, this age is 65. Moving to the next cell to the right, we can see that the characteristic level of 65-year-olds in schedule $r$ is 100 . The third step is to move to schedule $s$ and find where the characteristic level is 100 . The alpha-age is then shown in the fourth step as the age in schedule $s$ at which the level of the characteristic is 100. In this example, then, the alpha-age of the 65-year-old person in schedule $r$ would be 55, using schedule $s$ as a standard.

If schedule $r$ were applied to a particular group in 2000 and schedule $s$ were applied to the same group in 1950, and the characteristic was a measure of physical strength, Table 1 would tell us that 65 -year-olds in 2000 were as strong as 55 -yearolds had been in 1950. In informal language, for physical strength, 65 would be the new 55.

Special cases of alpha-ages arise depending on which characteristic is used and which combination of $a, r$, and $s$ is held fixed, while other combinations are allowed to vary. In the following sections, we demonstrate the unifying power of this approach through examples.

\section{Prospective ages and measures}

We call alpha-ages that use remaining life expectancy as a characteristic "prospective ages;" and we call measures of population aging based on prospective ages "prospective measures" of aging. Here, the characteristic schedules are simply based on the $e_{x}$ columns of the life tables.

\subsection{Example 1: Prospective old-age thresholds for whole populations}

In Greek mythology, the Sphinx who was guarding the city of Thebes was said to have asked passers-by the following question: "What creature is four-footed in the morning, two-footed in the afternoon, and three-footed in the evening?" Travelers 
Table 1:

Hypothetical example of an alpha-age computation

\begin{tabular}{ccccc}
\hline \multicolumn{2}{c}{ From characteristic schedule $\boldsymbol{r}$} & \multicolumn{2}{c}{ From characteristic schedule $\boldsymbol{s}$} \\
\cline { 1 - 2 } $\boldsymbol{a}$ & Characteristic level, $\boldsymbol{k}$ & & Characteristic level, $\boldsymbol{k}$ & $\boldsymbol{\alpha}$ \\
\hline$\ldots$ & $\ldots$ & $\ldots$ & $\ldots$ \\
65 & 100 & & 100 & 55 \\
$\ldots$ & $\ldots$ & $\ldots$ & $\ldots$ \\
\hline
\end{tabular}

who failed to give the correct answer were immediately killed. Oedipus is said to have given the correct answer: namely, man, because babies crawl on all fours, adults walk on two feet, and elderly people use canes. The Sphinx's division of the human lifecycle into three phases appears to be so obvious that it may seem that there is little need to discuss it. Indeed, the conventional dependency ratio divides people into the same three categories as those used by the Sphinx. Yet if we probe this issue more deeply, the boundaries between the phases become murky. People do become old, but at what point in life does this happen? The UN measures of population aging set the old-age threshold at 60 or 65 , but such arbitrary cut-off points are certainly problematic.

Forty years ago, Ryder questioned the practice of setting the old-age threshold based on chronological age. He wrote:

We measure age in terms of the number of years elapsed since birth. This seems to be a useful and meaningful index of the stages of development from birth to maturity. Beyond maturity, however, such an index becomes progressively less useful as a clue to other important characteristics. To the extent that our concern with age is what it signifies about the degree of deterioration and dependence, it would seem sensible to consider the measurement of age not in terms of years elapsed since birth but rather in terms of the number of years remaining until death. (Ryder 1975)

In previous papers (Sanderson and Scherbov 2007, 2008b, 2010; Lutz, Sanderson and Scherbov 2008), we have followed Ryder's suggestion and have chosen to use an old-age threshold based on remaining years of life. In computing the proportions of populations who are old, the UN uses age 60 as its old-age threshold. In computing the old-age dependency ratio, it classifies people as old-age dependents after they have reached their $65^{\text {th }}$ birthday. Instead of using fixed chronological ages, we use alpha-ages based on a fixed remaining life expectancy. In this approach, people are categorized as being old based on the number of years they are expected to live, not on the number of years they have already lived. An old-age threshold based on remaining life expectancy is much more informative than an old-age 
Example 1:

Prospective old-age thresholds - Table 2 $\alpha=C_{s}^{-1}\left(C_{r}(a), \alpha=C_{s}^{-1}(15)\right)$

\begin{tabular}{ll}
\hline Characteristic $(\boldsymbol{C}())$ & Remaining life expectancy \\
\hline Constant & $\boldsymbol{a}$ and $\boldsymbol{r}$ \\
Parameters & $C_{r}(a)=15$ years \\
Variable & $\boldsymbol{s}$ \\
Parameters & $s$ is a set of life tables for Brazil, China, Germany, India, \\
& Japan, Mexico, Nigeria, the Russian Federation, and the \\
& United States for the years 1960, 1980, 2000, 2010, \\
& 2025, and 2050 (both sexes combined) \\
\hline
\end{tabular}

threshold that does not vary. Life expectancy changes over time, differs across countries, and varies across subgroups within countries. Old-age thresholds that take this variation into account are more informative. While it is useful to recognize the phases of the lifecycle by applying an age threshold that separates those who are old from those who are not, it is not realistic to assume that this threshold never changes over time, is the same for all countries of the world, and is the same for all population subgroups.

In Example 1, we show how alpha-ages can be used to compute prospective oldage thresholds. In this case, $a$ and $r$ are chosen so that $C_{r}(a)=15$ years. Fifteen years was roughly the remaining life expectancy at age 65 in many low-mortality countries around 1970. In the example, $s$ is a set of life tables for Brazil, China, Germany, India, Japan, Mexico, Nigeria, the Russian Federation, and the United States for the years 1960, 1980, 2000, 2010, 2025, and 2050. These countries were chosen on the basis of population size and geographical representativeness.

The old-age thresholds in Table 2 all correspond to the same level of the characteristic, in this case, 15 years of remaining life expectancy. Therefore, the alpha-ages in Table 2 are all constant characteristic ages. In 1960, the old-age threshold in the USA was relatively high, at 64.2; while the old-age threshold in the Russian Federation was close behind, at 63.6; and the old-age threshold in Japan was 62.0. By 2000, the situation had changed. Japan had leapt ahead to achieve a threshold age of 71.1. The mortality crisis in the Russian Federation is evident in the table: the country's old-age threshold fell to 62.4. In other words, in 2000, a 62year-old in the Russian Federation had the same expected remaining years of life as a 71.1-year-old in Japan. The table shows that the old-age threshold increased rapidly in China as well, from 53.9 in 1960 to 64.5 in 2000.

If we were to accept the conventional view that the old-age threshold should be fixed at age 60 or at age 65 , we would have to ignore the substantial changes in life expectancies over time and the differences from place to place. There is no reason to 
Table 2:

Old-age thresholds

\begin{tabular}{lcccccc}
\hline & $\mathbf{1 9 6 0}$ & $\mathbf{1 9 8 0}$ & $\mathbf{2 0 0 0}$ & $\mathbf{2 0 1 0}$ & $\mathbf{2 0 2 5}$ & $\mathbf{2 0 5 0}$ \\
\hline Brazil & 62.3 & 63.8 & 67.6 & 69.1 & 71.1 & 73.6 \\
China & 53.9 & 63.1 & 64.5 & 65.7 & 66.5 & 68.4 \\
Germany & 62.9 & 64.4 & 68.3 & 70.0 & 71.5 & 73.8 \\
India & 55.9 & 59.8 & 61.4 & 62.7 & 63.7 & 65.5 \\
Japan & 62.0 & 66.5 & 71.1 & 72.8 & 74.5 & 76.9 \\
Mexico & 63.5 & 66.2 & 68.4 & 69.6 & 71.4 & 73.8 \\
Nigeria & 54.7 & 57.3 & 57.1 & 57.7 & 59.2 & 61.3 \\
Russian Fed. & 63.6 & 64.0 & 62.4 & 63.8 & 64.6 & 66.1 \\
USA & 64.2 & 66.9 & 68.7 & 70.3 & 71.4 & 73.3 \\
\hline
\end{tabular}

Source: Scherbov and Sanderson (2014), Table Re-Ageing 1.

Note: The underlying data are from United Nations (2013b).

Old-age thresholds are alpha-ages where the characteristic, remaining life expectancy, is equal to 15 years.

accept fixed old-age thresholds since alpha-age thresholds have now been computed for all UN countries (Scherbov and Sanderson 2014).

The proportions of populations who are old are shown in Table 3 for the same nine countries and the same six years using the prospective old-age thresholds in Table 2, and the fixed age of 65 upon which many conventional measures are based. The proportion old is one of the most frequently used measures of population aging, and in Table 3, it is clear that those proportions differ considerably depending on whether the old-age threshold is adjusted for life expectancy differences using alpha-ages. For example, the conventional proportion old in China is projected to increase from 0.040 in 1960 to 0.239 in 2050 . The prospective proportion old is also forecasted to increase, but much more slowly, from 0.109 in 1960 to 0.192 in 2050. Substantial differences in the growth in the proportion old can be seen in all of the countries listed in Table 3, except for the Russian Federation, where the changes in life expectancy have been relatively minor. The projected proportions old for all UN countries can be found in Scherbov and Sanderson (2014). Measures of population aging using prospective old-age thresholds can also be found in Emelyanova and Rautio (2017), Stojilkovic Gnjatovic (2017), and Basten-Gietel et al. (2017).

\subsection{Example 2: Prospective median ages}

A commonly used measure of population aging is the change in the median age. The prospective median age is the age in the standard life table, $s$, where individuals have the same remaining life expectancy as the individuals at the median age in the population associated with index $r$. 
Table 3:

Prospective and conventional proportions old

\begin{tabular}{lcccccc}
\hline A. Prospective proportions old & & & & \\
& $\mathbf{1 9 6 0}$ & $\mathbf{1 9 8 0}$ & $\mathbf{2 0 0 0}$ & $\mathbf{2 0 1 0}$ & $\mathbf{2 0 2 5}$ & $\mathbf{2 0 5 0}$ \\
\hline Brazil & 0.044 & 0.047 & 0.044 & 0.049 & 0.066 & 0.123 \\
China & 0.109 & 0.060 & 0.072 & 0.079 & 0.119 & 0.192 \\
Germany & 0.137 & 0.160 & 0.129 & 0.150 & 0.163 & 0.215 \\
India & 0.075 & 0.060 & 0.061 & 0.062 & 0.081 & 0.122 \\
Japan & 0.075 & 0.080 & 0.105 & 0.133 & 0.182 & 0.203 \\
Mexico & 0.039 & 0.035 & 0.037 & 0.040 & 0.055 & 0.114 \\
Nigeria & 0.077 & 0.060 & 0.060 & 0.055 & 0.049 & 0.054 \\
Russian Fed. & 0.069 & 0.109 & 0.156 & 0.141 & 0.172 & 0.188 \\
USA & 0.098 & 0.097 & 0.098 & 0.089 & 0.113 & 0.134 \\
\hline B. Conventional proportions & $\mathbf{o l d}$ & & & \\
& $\mathbf{1 9 6 0}$ & $\mathbf{1 9 8 0}$ & $\mathbf{2 0 0 0}$ & $\mathbf{2 0 1 0}$ & $\mathbf{2 0 2 5}$ & $\mathbf{2 0 5 0}$ \\
\hline Brazil & 0.033 & 0.042 & 0.055 & 0.069 & 0.114 & 0.225 \\
China & 0.040 & 0.051 & 0.069 & 0.084 & 0.135 & 0.239 \\
Germany & 0.114 & 0.156 & 0.163 & 0.208 & 0.251 & 0.327 \\
India & 0.031 & 0.036 & 0.044 & 0.051 & 0.072 & 0.127 \\
Japan & 0.057 & 0.090 & 0.172 & 0.230 & 0.296 & 0.366 \\
Mexico & 0.034 & 0.038 & 0.049 & 0.060 & 0.096 & 0.202 \\
Nigeria & 0.028 & 0.028 & 0.028 & 0.027 & 0.028 & 0.038 \\
Russian Fed. & 0.061 & 0.102 & 0.124 & 0.131 & 0.167 & 0.205 \\
USA & 0.091 & 0.113 & 0.124 & 0.131 & 0.186 & 0.214 \\
\hline
\end{tabular}

Source: Scherbov and Sanderson (2014), Table Re-Ageing 1.

Note: The underlying data are from United Nations (2013b). Prospective proportions old are proportions of the population who are at or above the prospective old-age threshold in Table 2. Conventional old-age thresholds are at age 65 and conventional proportions old are from United Nations (2013b).

Conventional and prospective median ages for selected countries are shown in Table 4. The most striking feature of that table is that it shows that conventional and prospective median ages can move in opposite directions (Sanderson and Scherbov 2005). For example, the conventional median age of the Mexican population in 1960 was 17.0 years $\left(a_{\text {median_r }}=17.0\right.$, and $\left.r=1960\right)$. The corresponding prospective median age using the Mexican life table of 2010 as a standard $(s=2010)$ was 28.1. This means that the remaining life expectancy of a 17.0-year-old Mexican in 1960 was the same as that of a 28.1-year-old Mexican in 2010. By 2010, the conventional median age of Mexicans rose to 25.9. Since $r$ and $s$ are the same in 2010, the prospective median age and the conventional median age are the same in that year. Therefore, while the conventional median age rose from 17.0 to 25.9 over the period 1960 to 2010 , the prospective median age fell from 28.1 to 25.9. 
Example 2:

Prospective median age - Table 4

$\alpha_{\text {median }}=C_{s}^{-1}\left(C_{r}\left(a_{\text {median } r}\right)\right)$

\begin{tabular}{ll}
\hline Characteristic $(\boldsymbol{C}())$ & Remaining life expectancy \\
\hline Constant & $\boldsymbol{s}$ \\
Parameters & $s$ is the life table for the specified country for 2010. \\
Variable & $\boldsymbol{a}$ and $\boldsymbol{r}$ \\
Parameters & $a_{\text {median_ } r}$ is the median age in the population associated \\
& with index $r$. \\
& $r$ is a set of life tables (for both sexes) for \\
& Brazil, China, Germany, India, Japan, Mexico, the \\
& Russian Federation, and the USA for the years 1960, \\
& 1980, 2000, 2010, 2025, and 2050. \\
\hline
\end{tabular}

Table 4:

Median age (MA) and prospective median age (PMA)

\begin{tabular}{|c|c|c|c|c|c|c|c|c|}
\hline & \multicolumn{2}{|c|}{ Brazil } & \multicolumn{2}{|c|}{ China } & \multicolumn{2}{|c|}{ Germany } & \multicolumn{2}{|c|}{ India } \\
\hline & MA & PMA & MA & PMA & MA & PMA & MA & PMA \\
\hline 1960 & $5 . J$ & 28.1 & 1.3 & 38.2 & 34.8 & 42.1 & 0.5 & 34.0 \\
\hline 1980 & 20.3 & 26.1 & 22.0 & 26.3 & 36.8 & 42.6 & 20.2 & 24.5 \\
\hline 2000 & 25.3 & 27.3 & 29.6 & 31.4 & 39.9 & 41.9 & 23.0 & 24.7 \\
\hline 2010 & 29.0 & 29.0 & 34.6 & 34.6 & 44.3 & 44.3 & 25.5 & 25.5 \\
\hline 2025 & 35.3 & 32.5 & 39.6 & 38.4 & 48.4 & 46.4 & 29.9 & 28.2 \\
\hline \multirow[t]{3}{*}{2050} & 44.5 & 37.9 & 46.2 & 42.8 & 51.5 & 46.6 & 36.7 & 32.8 \\
\hline & \multicolumn{2}{|c|}{ Japan } & \multicolumn{2}{|c|}{ Mexico } & \multicolumn{2}{|c|}{ Russian Fed. } & \multicolumn{2}{|c|}{ United Sates } \\
\hline & MA & PMA & MA & PMA & MA & PMA & MA & PMA \\
\hline 1960 & 25.5 & 37.5 & 17.0 & 28.1 & 27.1 & 23.9 & 29.6 & 36.4 \\
\hline 1980 & 32.6 & 38.8 & 17.3 & 24.2 & 31.1 & 29.3 & 30.1 & 34.1 \\
\hline 2000 & 41.4 & 43.2 & 23.0 & 24.6 & 36.6 & 38.0 & 35.3 & 36.9 \\
\hline 2010 & 44.9 & 44.9 & 25.9 & 25.9 & 37.9 & 37.9 & 37.1 & 37.1 \\
\hline 2025 & 50.2 & 48.2 & 31.5 & 29.0 & 40.8 & 39.3 & 38.8 & 37.0 \\
\hline 2050 & 53.4 & 48.5 & 41.9 & 36.2 & 41.6 & 37.6 & 40.6 & 36.2 \\
\hline
\end{tabular}

Source: Scherbov and Sanderson (2014), Table Re-Ageing 2.

Note: The underlying data are from United Nations (2013b).

PMA, or prospective median ages, are the ages in their country in 2000 at which people have the same remaining life expectancy as they have at the median age in the indicated year. 
Even though the Mexicans of median age were older in 2010, those older people had longer remaining life expectancies than their 17.0-year-old counterparts in 1960. The duration from birth to median age rose over that half century, as did the expected duration from the median age to death.

\subsection{Example 3: Prospective ages of 50-year-olds by educational subgroups}

Prospective ages can be used to investigate differences in aging trends across population subgroups. We examine these trends using prospective ages here and in the following two examples, where we study patterns of aging across educational subgroups for EU countries (Sanderson and Scherbov 2016). In Example 3, we present the prospective age of 50-year-olds by sex and educational attainment.

Eurostat has created a dataset on remaining life expectancies for 16 European countries for various years from 2007 to 2010 by sex using consistently defined educational attainment categories (Eurostat 2013). The low education category in the dataset includes people with pre-primary, primary, and lower secondary education (ISCED levels 0,1 , and 2). The medium education category includes individuals with upper secondary and post-secondary non-tertiary education (ISCED levels 3 and 4). The high education category includes individuals with tertiary education (ISCED levels 5 and 6). As patterns of aging may differ across geographic regions, the countries are divided into Western European countries (Denmark, Finland, Italy, Malta, Norway, Portugal, and Sweden) and Eastern European countries (Bulgaria, Croatia, the Czech Republic, Estonia, Hungary, Macedonia, Poland, Romania, and Slovenia).

Example 3:

Prospective ages of 50-year-olds by education - Table 5

$\alpha=C_{s}^{-1}\left(C_{r}(a)\right)$

\begin{tabular}{ll}
\hline Characteristic $(\boldsymbol{C}())$ & Remaining life expectancy \\
\hline Constant & $\boldsymbol{a}$ and $\boldsymbol{s}$ \\
Parameters & $\begin{array}{l}a=50 \text { years old, } \\
s \text { are sex-specific life tables for Italians with at least } \\
\text { some tertiary education }\end{array}$ \\
Variable & $\boldsymbol{r}$ \\
Parameters & $r$ is a set of life tables for 16 European countries by sex \\
& and level of education (latest available year) \\
\hline
\end{tabular}

In this analysis, chronological age, $a$, is held constant at age 50, and $s$ refers to the sex-specific life table for Italians with at least some tertiary education. In 
Table 5:

Prospective ages of 50-year-olds by education and gender (Italians with tertiary education are used as the standard)

\begin{tabular}{|c|c|c|c|c|c|c|}
\hline & \multicolumn{3}{|c|}{ Males } & \multicolumn{3}{|c|}{ Females } \\
\hline & Low Ed. & Med. Ed. & High Ed. & Low Ed. & Med. Ed. & High Ed. \\
\hline \multicolumn{7}{|l|}{ Eastern Europe } \\
\hline Bulgaria & 65.43 & 57.95 & 55.70 & 60.66 & 56.51 & 55.33 \\
\hline Croatia & 60.08 & 58.22 & 53.98 & 56.32 & 56.90 & 53.86 \\
\hline Czech Republic & 66.64 & 56.92 & 52.59 & 56.15 & 55.33 & 52.76 \\
\hline Estonia & 66.11 & 59.10 & 55.60 & 58.44 & 55.80 & 52.53 \\
\hline FYR Macedonia & 60.84 & 58.12 & 54.67 & 59.32 & 57.83 & 55.85 \\
\hline Hungary & 66.74 & 58.05 & 55.77 & 59.36 & 55.73 & 55.39 \\
\hline Poland & 61.95 & 58.49 & 53.97 & 56.27 & 55.16 & 53.25 \\
\hline Romania & 63.97 & 58.52 & 57.09 & 58.76 & 56.57 & 55.97 \\
\hline Slovenia & 60.45 & 54.52 & 51.90 & 54.64 & 52.22 & 51.32 \\
\hline Average & 63.58 & 57.77 & 54.58 & 57.77 & 55.78 & 54.03 \\
\hline std. dev. & 2.78 & 1.35 & 1.65 & 1.98 & 1.58 & 1.68 \\
\hline \multicolumn{7}{|l|}{ Western Europe } \\
\hline Denmark & 56.82 & 54.78 & 52.77 & 56.27 & 54.30 & 53.33 \\
\hline Finland & 56.02 & 54.75 & 52.20 & 53.56 & 52.40 & 51.56 \\
\hline Italy & 53.99 & 50.15 & 50.00 & 52.19 & 50.16 & 50.00 \\
\hline Malta & 54.48 & 54.00 & 52.22 & 53.94 & 53.85 & 52.23 \\
\hline Norway & 55.48 & 52.85 & 50.95 & 54.25 & 52.49 & 51.61 \\
\hline Portugal & 55.04 & 53.84 & 52.98 & 53.25 & 52.72 & 52.56 \\
\hline Sweden & 53.74 & 52.56 & 51.08 & 53.82 & 52.69 & 51.61 \\
\hline Average & 55.08 & 53.28 & 51.74 & 53.90 & 52.66 & 51.84 \\
\hline std. dev. & 1.11 & 1.62 & 1.09 & 1.24 & 1.32 & 1.04 \\
\hline
\end{tabular}

Source: Sanderson and Scherbov (2016), Table 2.

the Eurostat dataset, these Italians generally had the highest life expectancies. The parameter that varies is $r$. This parameter can stand for any of the 96 possible life tables (16 countries, by two genders and by three educational categories). The alphaages that are calculated in this way are the ages of Italians with at least some tertiary education who have the same remaining life expectancy as 50-year-olds in one of the 96 possible life tables, $r$. Since Italians with at least some tertiary education had the highest remaining life expectancies, all of the remaining life expectancies at age 50 will be lower than those for the more educated 50-year-olds Italians, and the calculated alpha-ages will all be above 50 .

In Table 5, the average alpha-ages of 50-year-old men and women with higher levels of education in the Western European countries were 51.74 and 51.84, 
respectively. The average size of the gaps between these average ages and those of the more educated Italians was less than two years. The average alpha-ages of 50year-old men and women with higher levels of education in the Eastern European countries were 54.58 and 54.03, respectively. The gender differences for people in the highest educational group is small in both regions. In contrast, the gender differences in the average alpha-ages of people in the lowest educational group are much larger in the Eastern European countries than in the Western European countries. In that educational group, the mean alpha-age of women in the Western European countries was 53.90, and the corresponding figure for men was only 1.18 years higher. In the Eastern European countries, the mean alpha-age of less educated women was 57.77, and the corresponding figure for men was 5.81 years higher. Using alpha-ages allows for very natural quantifications of subgroup differences such as these. A more detailed discussion of these difference can be found in Sanderson and Scherbov (2016).

\subsection{Example 4: Age difference trajectories by educational subgroups}

In Example 4, we utilize a new concept that we call "age difference trajectories." Age difference trajectories are the relationships between chronological age, on the one hand; and the difference between the alpha-age and the chronological age, on the other. The trajectories do not show how fast a subgroup ages in an absolute sense, only how well a particular subgroup is doing at each chronological age relative to a reference subgroup. As before, our reference subgroup here consists of Italians with high education.

\section{Example 4:}

Age difference trajectories by sex and education - Figures 1-4

$C_{s}^{-1}\left(C_{r}(a)\right)-a=\alpha-a$

\begin{tabular}{ll}
\hline Characteristic $(\boldsymbol{C}())$ & Remaining life expectancy \\
\hline Constant & $\boldsymbol{r}$ and $\boldsymbol{s}$ \\
Parameters & $\boldsymbol{r}$ is any one of the set of 16 European life tables (see \\
& Table 5) by sex and level of education (latest available \\
& year), \\
& $s$ is a sex-specific life table for Italians with at least \\
& some tertiary education \\
Variable & $\boldsymbol{a}$ \\
Parameters & $a$ is a set of ages between 30 and 66 \\
\hline
\end{tabular}




\section{Figure 1:}

Age difference trajectories, Norway, 2010 by level of education
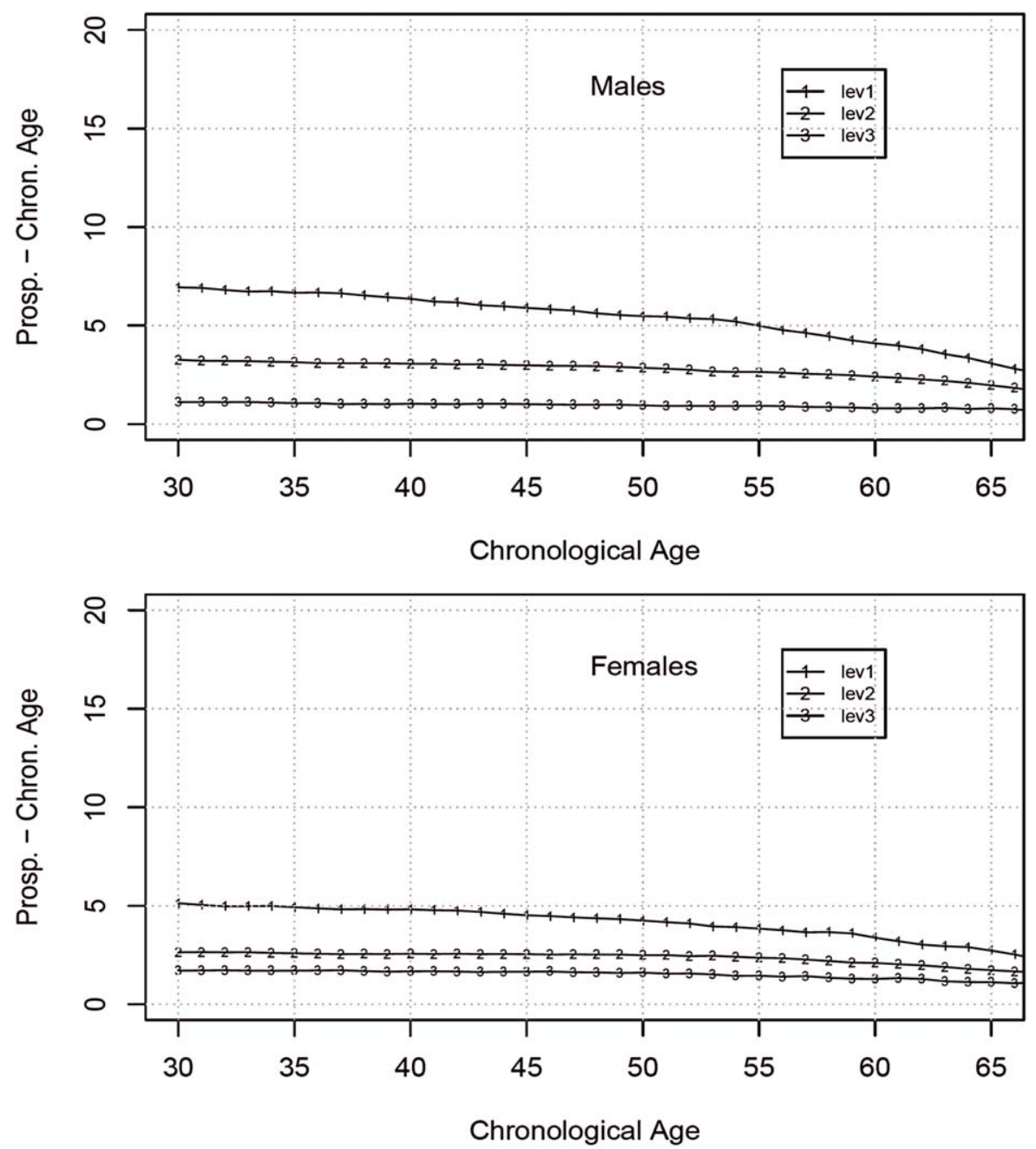

Note: The characteristic is the remaining life expectancy at each age. The standard schedule is for Italians with tertiary education. lev1 refers to people with pre-primary, primary, and lower secondary education (ISCED 0, 1 , and 2); lev2 refers to people with upper secondary and post non-tertiary education (ISCED 3 and 4); lev 3 refers to people with tertiary education (ISCED 5 and 6).

Source: Authors' calculations.

In Figures 1 through 4, we plot chronological age on the $\mathrm{x}$-axis, and the difference between prospective age and chronological age on the y-axis. In other words, chronological age, $a$, is on the x-axis; and $\alpha-a$ is on the $\mathrm{y}$-axis. The difference between prospective age and chronological age is a measure of the extent to which 
Figure 2:

Age difference trajectories, Denmark, 2010 by level of education
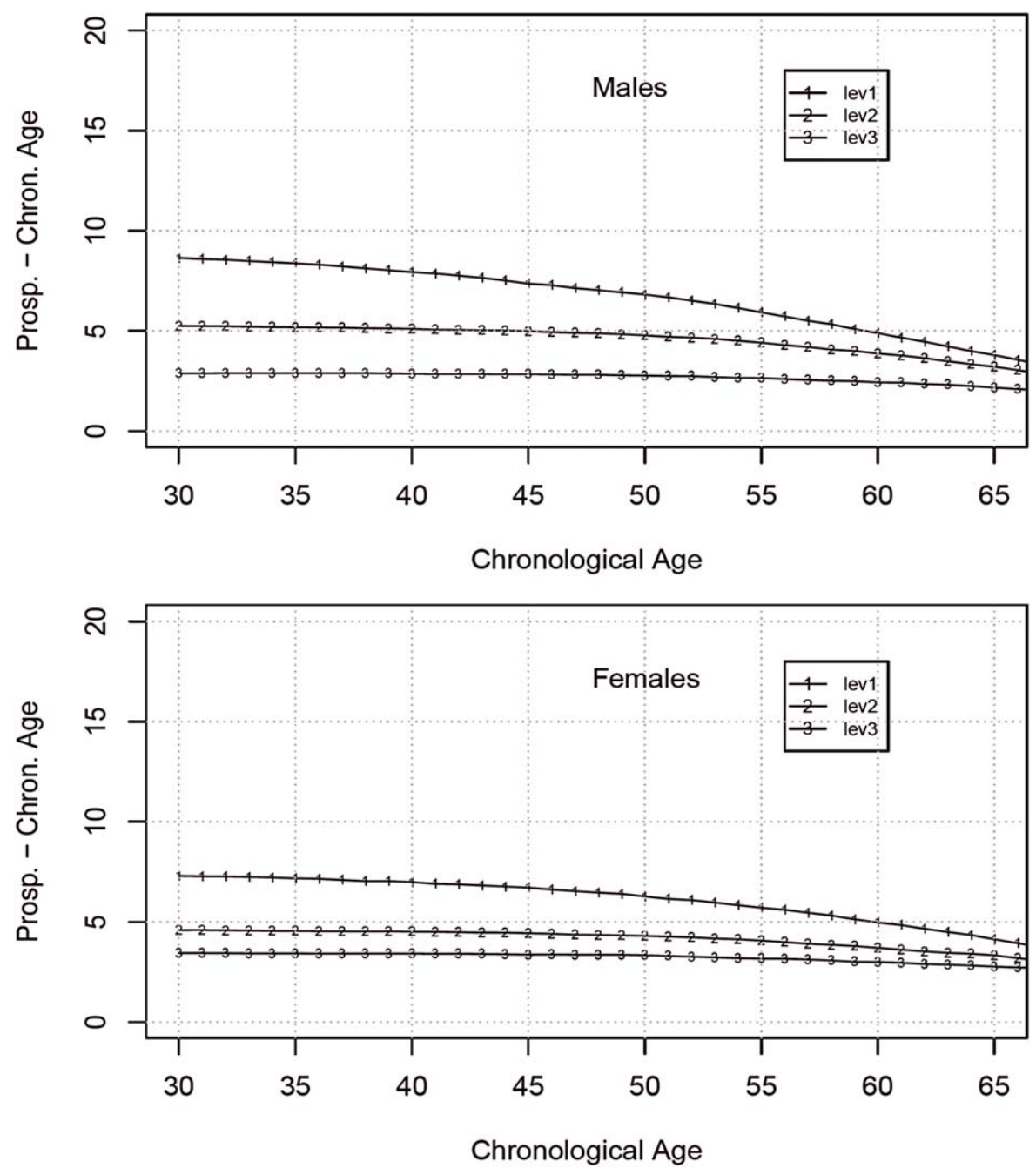

Note: The characteristic is the remaining life expectancy at each age. The standard schedule is for Italians with tertiary education. lev1 refers to people with pre-primary, primary, and lower secondary education (ISCED 0, 1, and 2); lev2 refers to people with upper secondary and post non-tertiary education (ISCED 3 and 4 ); lev 3 refers to people with tertiary education (ISCED 5 and 6). Source: Authors' calculations.

the subgroup lags behind the Italians with high education. These age difference trajectories translate differences in patterns of life expectancies over ages into a form that is easy to visualize, interpret, and analyze. Because age difference trajectories 
Figure 3:

Age difference trajectories, Slovenia, 2010 by level of education
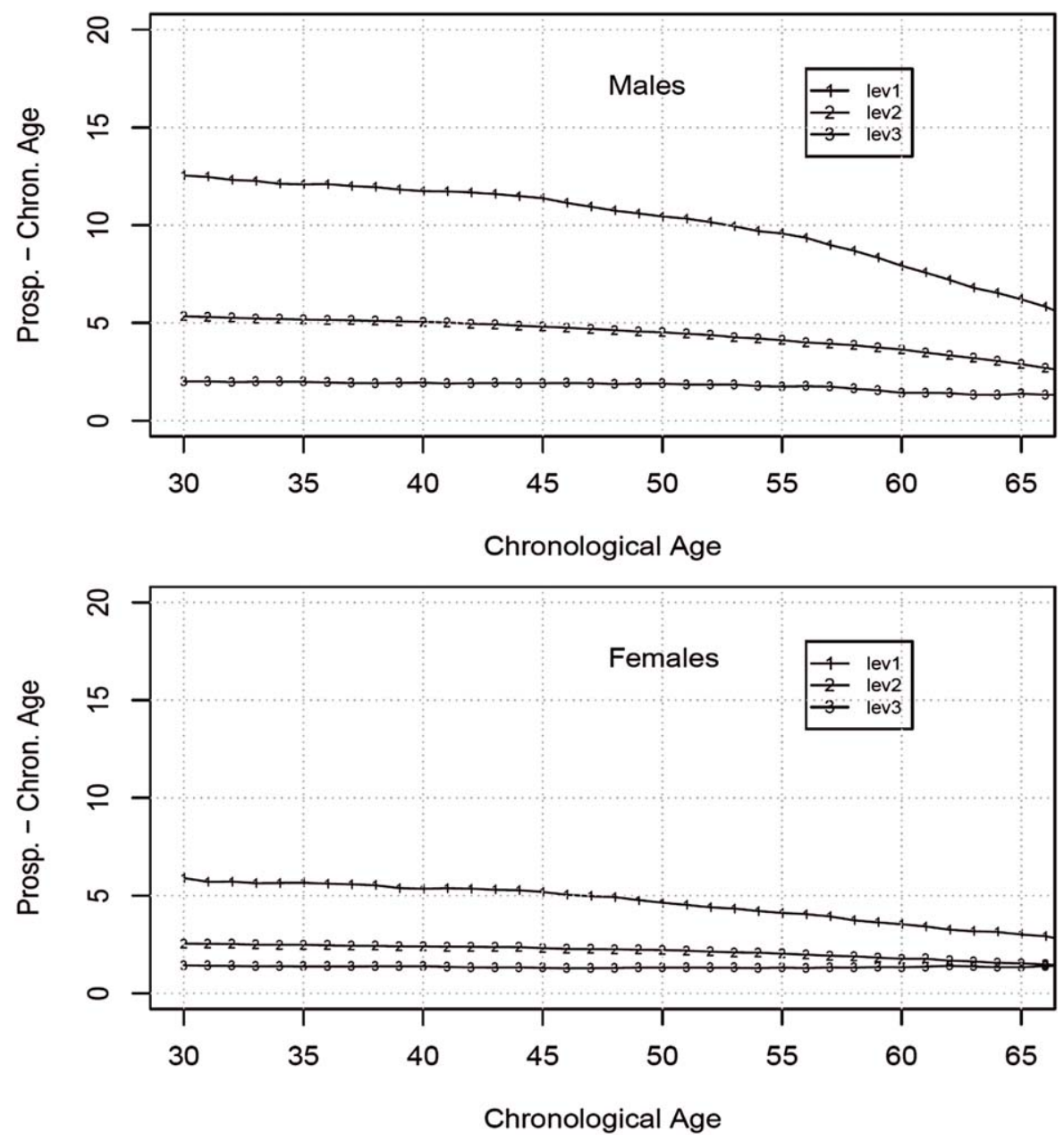

Note: The characteristic is the remaining life expectancy at each age. The standard schedule is for Italians with tertiary education. lev1 refers to people with pre-primary, primary, and lower secondary education (ISCED 0, 1 , and 2); lev2 refers to people with upper secondary and post non-tertiary education (ISCED 3 and 4); lev 3 refers to people with tertiary education (ISCED 5 and 6).

Source: Authors' calculations.

are relationships across ages, we can analyze how those trajectories differ in terms of both their levels and their slopes. Differences in levels tell us how far behind the subgroup is, while differences in slopes tell us whether the group is getting closer to or further from the reference group with increasing chronological age. 
Figure 4:

Age difference trajectories, Macedonia, 2010 by level of education
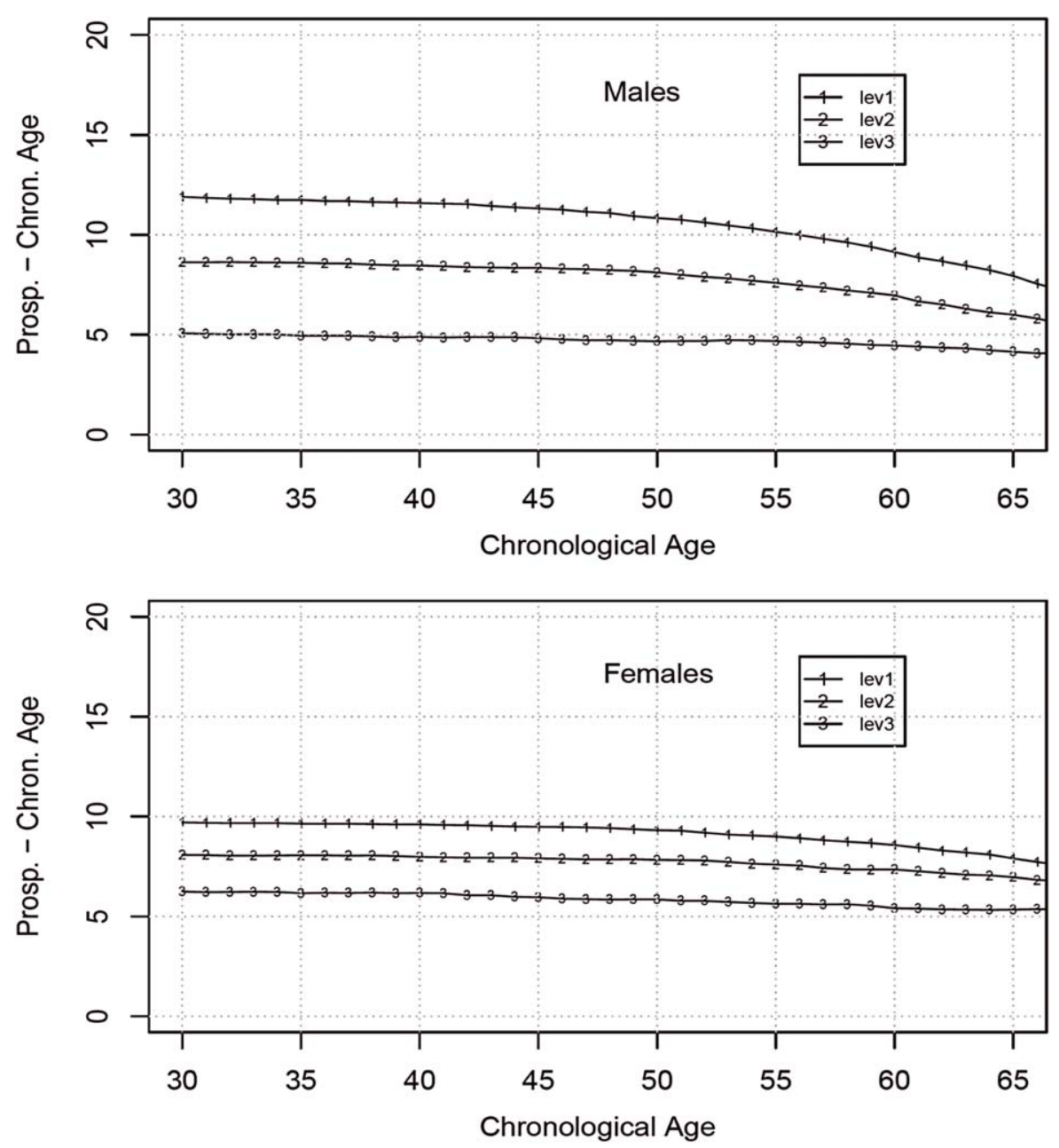

Note: The characteristic is the remaining life expectancy at each age. The standard schedule is for Italians with tertiary education. lev1 refers to people with pre-primary, primary, and lower secondary education (ISCED 0, 1 , and 2); lev2 refers to people with upper secondary and post non-tertiary education (ISCED 3 and 4); lev 3 refers to people with tertiary education (ISCED 5 and 6).

Source: Authors' calculations.

Figures 1 and 2 display the age difference trajectories for two Western European countries that have a common history: Norway and Denmark. Figures 3 and 4 show the age difference trajectories of two Eastern European countries that have a common history: (FYR) Macedonia and Slovenia. Italians with high education in 2009 are the reference group, $s$, from which all alpha-ages are computed. Each 
figure has three lines. The lines labeled 1,2, and 3 refer to the respective trajectories for people with low, medium, and high educational attainment.

Norway is a country with a high life expectancy and a high per capita income. Even there, however, we see that, for men at age 30 with low education, the gap between the prospective and the chronological age is around seven years. We can see from the figure that the slope of the trajectory for less educated men is negative, which indicates that there is some degree of convergence toward the Italian standard with increasing chronological age. Norwegian men with high education have trajectories that are only slightly above zero, which indicates that they are similar to Italian men with high education at all ages. The trajectories for Norwegian women are similar, albeit with smaller differences across educational groups. The general patterns of the trajectories for Danish men and women are similar to those of their Norwegian counterparts, with the graphs for all three levels of education shifted upward by about three years. It is likely that this difference is due to differences in rates of smoking and alcohol consumption (Christensen et al. 2010).

Figure 3 shows the trajectories for Slovenia. Slovenian men and women with high education have age difference trajectories with slopes of approximately zero. Both of those trajectories are lower than those of their Danish counterparts, which indicates that they are closer to the trajectories of the Italian leaders. Slovenian men with medium education have trajectories that are almost identical to those of their Danish counterparts, while Slovenian women with medium education have trajectories that are clearly lower than those of their Danish counterparts. Slovenian women with low education also have lower trajectories than Danish women with low education. In all of the groups, except for the group of men with low education, Slovenians have age difference trajectories that are lower than those of their Danish counterparts. The situation of the Macedonians (see Figure 4) is quite different from those of the people in the other three countries. The trajectories for Macedonian women in all three age groups are comparatively high, and there is much less convergence with age across the educational subgroups. For Macedonian men, the high levels of the trajectories for those with medium and high education stand out.

\section{Health- and disability-based ages and measures}

Health is difficult to quantify, in part because it has so many dimensions, and in part because some of those dimensions are necessarily subjective. One rough approximation to health on a population level is the probability of surviving for the next five years. This characteristic has two advantages: (1) it can be measured or estimated reasonably accurately, and (2) it is comparable over time and place. Using the probability of surviving for the next five years as the characteristic of interest, we can calculate health-based age difference trajectories. 
Example 5:

Survival-based age difference trajectories for countries - Figure 5 (own country standards)

$C_{s}^{-1}\left(C_{r}(a)\right)-a=\alpha-a$

\begin{tabular}{|c|c|}
\hline Characteristic $(C())$ & Probability of surviving for the next five years $\left(l_{x+5} / l_{x}\right)$ \\
\hline Constant Parameters & $\begin{array}{l}s \\
s \text { is a sex-specific life table for the country of interest } \\
\text { in } 2000\end{array}$ \\
\hline Variable Parameters & $\begin{array}{l}a \text { and } \boldsymbol{r} \\
a \text { is a set of ages between } 40 \text { and } 80, \\
r \text { is one of a set of sex-specific life tables for the country } \\
\text { of interest for the years } 1953,1960,1970, \ldots, 2010\end{array}$ \\
\hline
\end{tabular}

\section{Example 6:}

Survival-based age difference trajectories for countries - Figure 6 (Japan in 2010 as a standard)

$C_{s}^{-1}\left(C_{r}(a)\right)-a=\alpha-a$

\begin{tabular}{ll}
\hline Characteristic $(\boldsymbol{C}())$ & Probability of surviving for the next five years $\left(\boldsymbol{l}_{\boldsymbol{x}+\boldsymbol{5}} / \boldsymbol{l}_{\boldsymbol{x}}\right)$ \\
\hline Constant & $\boldsymbol{s}$ \\
Parameters & $s$ is a sex-specific life table for Japan in 2000 \\
Variable & $\boldsymbol{a}$ and $\boldsymbol{r}$ \\
Parameters & $\begin{array}{l}\boldsymbol{a} \text { is a set of ages between } 40 \text { and } 80, \\
\\
\end{array}$ \\
& $\boldsymbol{r}$ is one of a set of sex-specific life tables for the country \\
&
\end{tabular}

\subsection{Examples 5 and 6: Survival-based age difference trajectories}

Survival rate-based age difference trajectories are presented in Figure 5 for Brazil, China, Germany, India, Japan, Mexico, Nigeria, the Russian Federation, and the USA using life tables for 1953, and at 10-year intervals from 1960 through 2010. Country life tables for 2000 are used as standards $s$, and the differences between alpha-ages and chronological ages in 2000 are shown for ages 40 to 80 . This example provides a visualization of the changes in the survival rates across ages and over time within countries. Two distinct patterns are evident. In the developing countries of Brazil, China, India, Mexico, and Nigeria, improvements in five-year survival rates have been faster at age 40 than at later ages. In China and India, in particular, large improvements in survival rates are seen after 1960. In Germany, 
Figure 5:

Age difference trajectories, Brazil, China, Germany, India, Japan, Mexico, Nigeria, Russian Federation, and the USA for 1953, 1960, 1970, ..., 2010

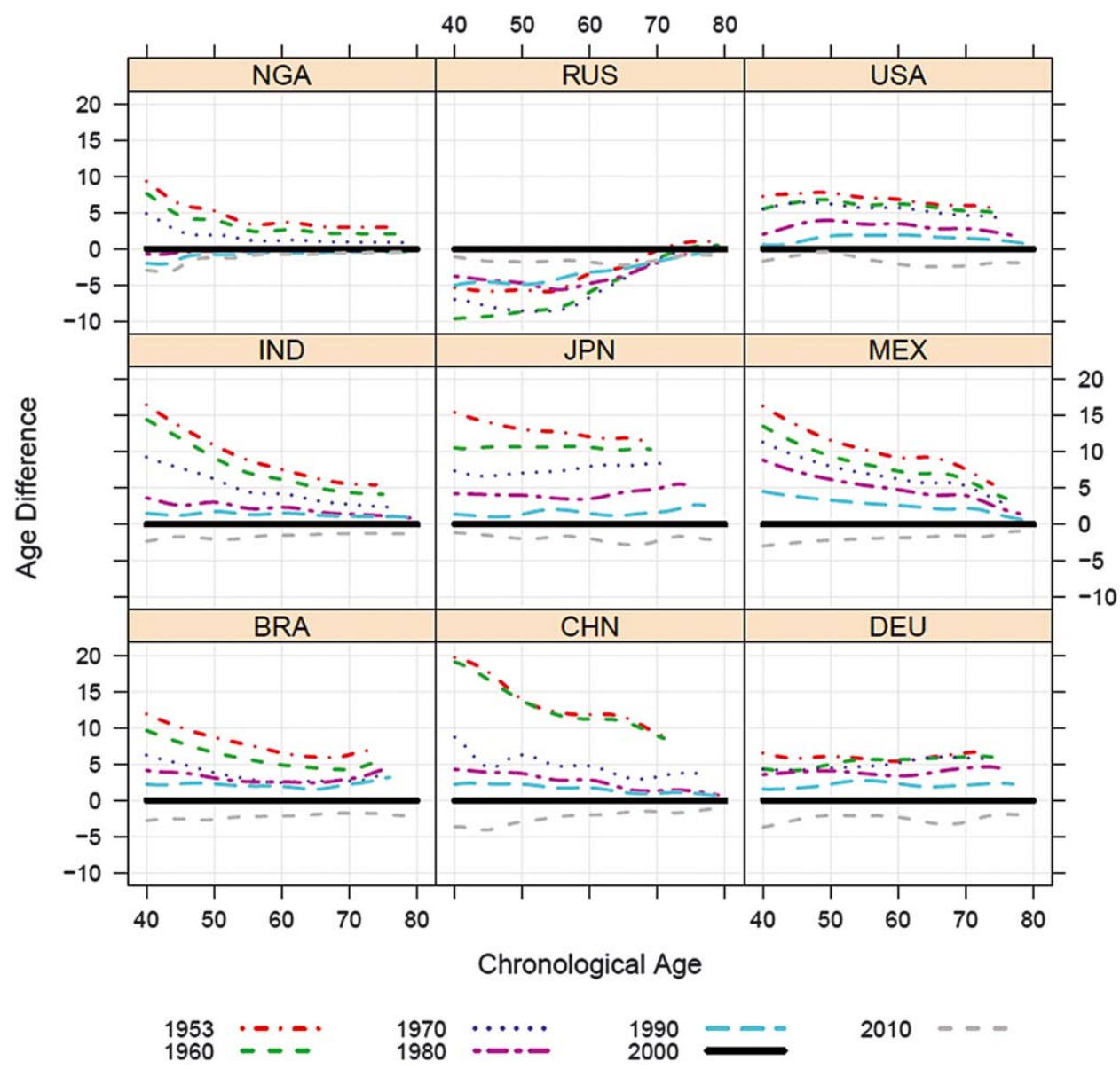

Note: Characteristic is the five-year survival rate at each age. The standard schedule, $s$, is the schedule for each country individually in 2000 .

Source: Authors' calculations based on United Nations (2013b).

Japan, and the USA, the age trajectories in recent decades are roughly parallel lines that move downward over time. The graph for the Russian Federation is distinctly different, reflecting the effects of the mortality crisis after 1991.

Figure 6 shows the same survival rate-based trajectories using Japanese life tables in 2010 as the standard. Japan has some of the highest age-specific survival rates in the world. Age trajectories based on a single standard allow for the visualization of the evolution of age-specific survival rates for various ages relative to the 


\section{Figure 6:}

Age difference trajectories, Brazil, China, Germany, India, Japan, Mexico, Nigeria, Russian Federation, and the USA for 1953, 1960, 1970, .., 2010

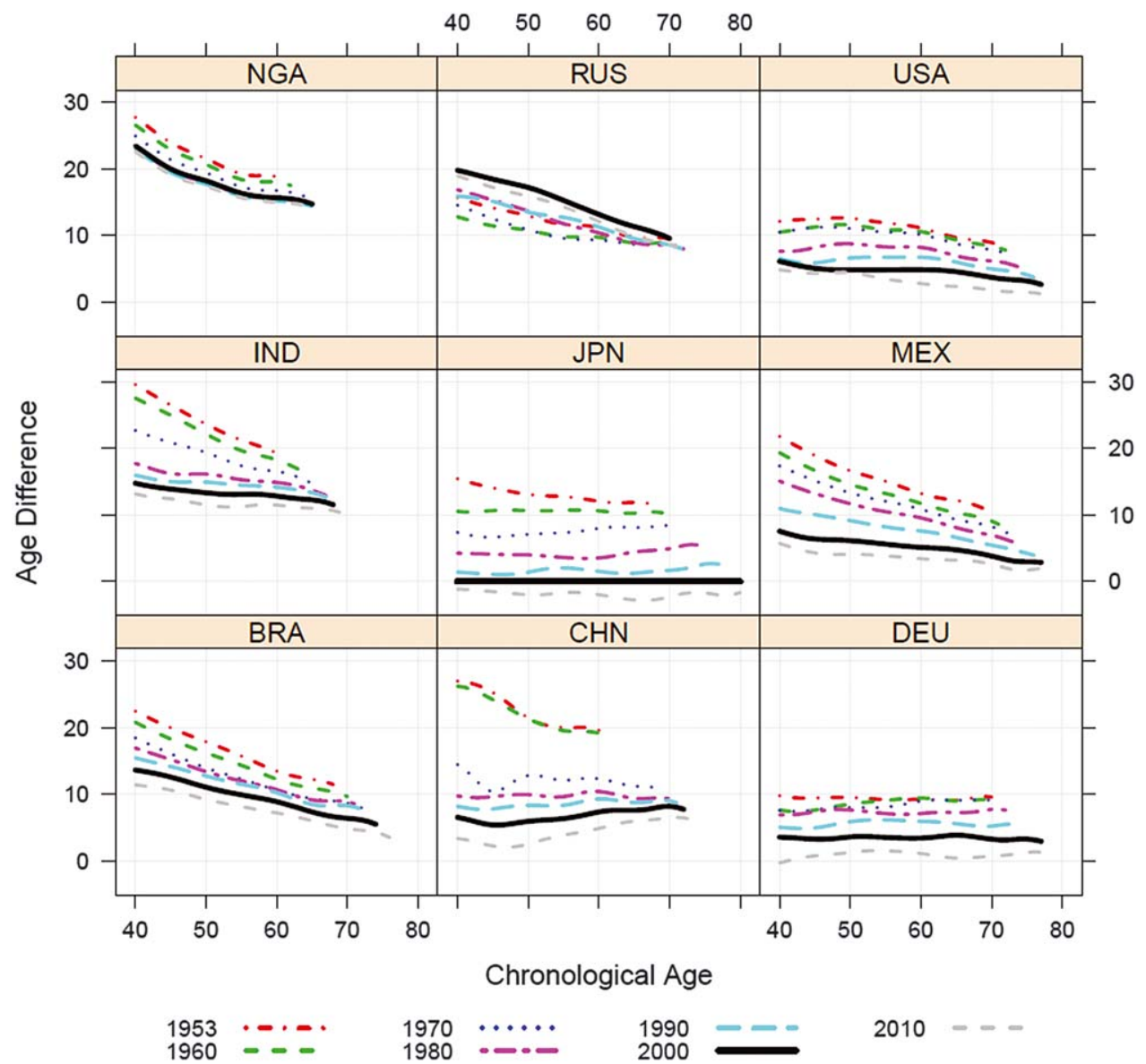

Note: Characteristic is the five-year survival rate at each age. The standard schedule, $s$, is for Japan in 2000. Source: Authors' calculations based on United Nations (2013b).

corresponding rates of the world's leaders. For most countries, we see negatively sloped age trajectories that decline over time. In Germany, the age trajectories are nearly horizontal lines, which indicates that at each age, the survival rates have been changing in line with the Japanese standard rates. The age difference trajectory for the USA has a slightly negative slope, which indicates that the survival rates at younger ages are lower than those of the Japanese at older ages. The graph for the Russian Federation again reflects the mortality crisis in that country. In 2000, the survival rates at age 40 were lower in Russia than in any of the other nine countries 
shown except for Nigeria. The pattern for Japan itself is worth noting. From 1990 through 2010, the changes in the trajectory have been greater for people aged 60 and older than for people below age 60 . It will be interesting to see whether this pattern persists.

The pattern that is observed for China is distinctly different. In the data for 2000 and 2010, there is a distinctly positive slope in the trajectory, which indicates that when looking across ages, the Chinese survival rates have become progressively worse relative to those in Japan. This points to an issue that bears further investigation.

Example 7:

Alpha-ages based on proportions in self-reported good (bad) health $\alpha=C_{s}^{-1}\left(C_{r}(a)\right)$

\begin{tabular}{ll}
\hline Characteristic $(\boldsymbol{C}())$ & $\begin{array}{l}\text { Proportion of population in self-reported good } \\
\text { (bad) health }\end{array}$ \\
\hline $\begin{array}{l}\text { Constant } \\
\text { Parameters }\end{array}$ & $\begin{array}{l}s \\
\text { Vis the age-specific proportion of people in self-reported } \\
\text { good (bad) health in the EU-15 in } 2007\end{array}$ \\
Variable Parameters & $\begin{array}{l}\boldsymbol{a} \text { and } \boldsymbol{r} \\
a \text { is a set of ages between } 20 \text { and } 84, \\
r \text { is the age-specific proportion of people in self-reported } \\
\text { good (bad) health in the EU-15 in 2011. }\end{array}$ \\
\hline
\end{tabular}

\subsection{Example 7: Alpha-ages of those in good and in bad self-reported health}

The age-specific schedules of prevalence rates of health conditions quite naturally fall within the unifying framework presented here. For example, the age-specific proportions of European populations with three levels of self-reported health are available for European countries. To illustrate how these data can be used, characteristic schedules for the proportions of the population of the EU-15 in good self-reported health and in bad self-reported health were computed by sex for 2007 and 2011; the earliest and the latest years available at the time of writing ("EurOhex" 2015). Data on the proportions by five-year age groups were turned into characteristic schedules using linear regressions with observations set at the midpoints of age intervals using age, age squared, and a dummy variable for the year 2011 as independent variables. For each gender, alpha-ages were computed separately for proportions with good self-reported health and with bad self-reported heath. Women aged 61.6 had the same level of self-reported good health in 2011 
as their 60-year-old counterparts had in 2007. Meanwhile, women aged 62.2 had the same level of self-reported bad health in 2011 as their 60-year-old counterparts had in 2007. For men, the results were similar: over the period 2007 to 2011, there was a gain of roughly two years in alpha-ages for 60-year-olds using self-reported health as the characteristic. Demuru (2017) adjusted the prospective ages in Italy using survey data on self-reported health.

\section{Biomarker-based ages}

Surveys such as the Health and Retirement Study (HRS) and its sister surveys measure a wide range of population characteristics. Some of these characteristics are measured using self-reports, such as the age-specific proportions of people in good self-reported health, the subjective probabilities of surviving to some future age, and self-reports on disabilities and difficulties in accomplishing specific tasks. Other observations are based on various sorts of objective measurements, which can be divided into the following categories: (1) measurements of physical performance, such as hand grip strength, walking speed, speed of standing up from a sitting position, and the length of time a person can keep his balance in a certain position; (2) measurements of mental performance, such as immediate word recall, delayed word recall, the ability to subtract seven sequentially beginning with 100 , and verbal fluency; and (3) measurements of body chemistry, such as those derived from saliva and blood tests.

\section{Example 8:}

Alpha-ages of population subgroups based on hand grip strength - Table 6 $\alpha=C_{s}^{-1}\left(C_{r}(a)\right)$

\begin{tabular}{ll}
\hline Characteristic $(C())$ & Hand grip strength \\
\hline Constant & $r$ and $s$ \\
Parameters & $r$ is the age-specific hand grip strength of people in a \\
& specific gender and race group with more education \\
& $s$ is the age-specific hand grip strength of people in a \\
& specific gender and race group with less education \\
Variable Parameters & $\boldsymbol{a}$ \\
& $a$ is a set of ages between 60 and 80 \\
\hline
\end{tabular}


Table 6:

Alpha-ages based on hand grip strength for population subgroups

\begin{tabular}{cccccc}
\hline \multirow{2}{*}{$\begin{array}{c}\text { Reference age of } \\
\text { less educated }\end{array}$} & \multicolumn{2}{c}{ Whites - more educated } & & \multicolumn{2}{c}{ African Americans - more educated } \\
\cline { 2 - 3 } & Male & Female & & Male & Female \\
\hline 60 & $65.8(63.9,67.7)$ & $65.7(63.9,67.3)$ & & $57.6(53.4,61.4)$ & $64.7(60.5,68.2)$ \\
70 & $69.6(68.2,70.9)$ & $69.4(68.2,70.7)$ & & $63.4(60.3,66.3)$ & $68.5(65.3,71.3)$ \\
75 & $73.4(72.3,74.5)$ & $73.3(72.3,74.3)$ & & $69.2(66.5,71.6)$ & $72.3(69.5,74,8)$ \\
80 & $77.3(76.4,78.3)$ & $77.2(76.4,78.1)$ & & $74.7(71.9,77.6)$ & $76.1(73.3,79.0)$ \\
& $81.3(80.2,82.3)$ & $81.2(80.2,82.2)$ & & $80.3(76.9,83.9)$ & $80.0(76.5,83.7)$ \\
\hline
\end{tabular}

Source: Sanderson and Scherbov (2014), Table 1.

Note: Figures in parentheses show the 95-percent confidence intervals.

\subsection{Example 8: Alpha-ages of population subgroups based on hand grip strength}

Integrating this plethora of observations of different characteristics of people into a consistent picture of the aging process is a challenge. The concept of alpha-ages can be useful in this context, as different characteristics can be translated into alpha-ages that can be readily compared. For example, alpha-ages based on the characteristic of hand grip strength can be used to study the differences in the speed of aging among educational subgroups in the United States. Hand grip strength has been shown to be a predictor of subsequent mortality and morbidity (Leong et al. 2015; Al Snih et al. 2002; Ambrasat, Schupp and Wagner 2011).

In Sanderson and Scherbov (2014), we combined data from the 2006, 2008, 2010, and 2012 waves of the Health and Retirement Survey (HRS) on the hand grip strength levels of men and women aged 60 to 80 by race and level of education. Two educational groups were distinguished: those with less than a completed high school education and those with a completed high school education or more. Four characteristic schedules were created from these data (two genders cross-classified by two racial groups) using regressions with individual fixed effects, controlling for age, height, weight, and HRS wave.

The results are shown in Table 6. Hand grip strength increases with the level of education for both men and women. If we turn hand grip strength levels into alphaages, we can see, for example, that on average, the 69.4-year-old white women in the higher educational group have the same hand grip strength levels as the 65 -year-old women in the lower educational group. Using hand grip strength as the characteristic, we can observe that more educated white women aged less rapidly than less educated white women, as the former group had the same average hand grip strength level as the latter group more than four years later in life. A wide variety of measures of physical and mental performance can be analyzed in the same way. 


\subsection{Alpha-age and biological age}

Biological age is usually measured by combining blood- and saliva-based observations. Such measurements can be easily performed using alpha-ages. In a recent paper (Levine and Crimmins 2014), three biomarker-based measures namely, the allostatic load, the Framingham risk score, and the so-called "biological age" - were assessed to determine which one is the best predictor of subsequent 10-year mortality. Using 9,042 observations from the National Health and Nutrition Examination Survey III, Levine and Crimmins found that biological age was the best predictor. It is based on an index of nine individual observations: CRP, serum creatinine, Hba1c, albumin, total cholesterol, CMV, alkaline phosphatase, FEV1, urea nitrogen, and systolic blood pressure. All but the last of these observations are based on blood tests.

The methodology for the construction of biological age depends on two parameters for each of the biomarkers: namely, the constant term and the slope of the relationship between the biomarker and chronological age. Using the terminology in this paper, we have based our definition of biological age on nine characteristic functions. This methodology could represent a new approach to computing biological age. For each individual, alpha-ages are computed for a set of relevant characteristics, and are then combined. This approach could be used in the future as a simple and straightforward way of calculating biological age, especially as it makes it easy to test the relative importance of each of the biomarkers in forecasting mortality. The relationship between biomarkers and aging has also been studied in Rehkopf et al. (2017).

\section{Alpha-ages as intergenerationally equitable normal pension ages}

Up to this point, we have focused on the age-specific characteristics of people that are relevant for the study of population aging. We have provided examples in which we translated into alpha-ages characteristics as different as hand grip strength, fiveyear survival rates, remaining life expectancy, and self-reported health. Population aging is a multidimensional phenomenon, and the use of alpha-ages allows us to study those characteristics in a unified framework. In this section, we show how the range of applications of alpha-ages can be extended to the formulation of public policy.

The setting of normal pension ages is an important public policy decision. In almost all OECD countries, normal pension ages (or arrangements that have a similar effect) are currently being increased (OECD 2014, 2013, 2011). However, the rationale for such increases is often muddled. It is sometimes argued that normal pension ages must rise because governments would otherwise face severe fiscal difficulties. This rationale is unconvincing, and proposals to raise the normal 
pension age on the basis of such arguments tend to generate substantial public resistance. If the maintenance of current pension arrangements is considered socially desirable, then governments could raise the money to fund these pensions from a wide variety of sources, including higher taxes, lower expenditures on other activities, and improvements in the efficiency of the provision of public services. There is no particular reason why the people who are looking forward to receiving a pension should bear most of the burden of solving the government's fiscal problems. Raising the normal pension age just because pensions are expensive is a bit like reducing the number of schools because education is expensive.

In a situation in which life expectancy at older ages is growing, the maintenance of a fixed normal pension age is not socially desirable, because it results in intergenerational inequality. Thus, in such policy discussions, it is useful to have a simple and equitable benchmark that is easy to interpret, and that can be used to compare planned and potential increases in normal pension ages.

In Sanderson and Scherbov (2015), we formulated a simple example in which we produced an intergenerationally equitable normal pension age based on three principles: (1) the members of each cohort should receive pension benefit amounts equal to their contributions, (2) the generosity of the pension system (the ratio of the average pension benefit to the average income of those who contribute to the pension system, after the pension tax) should remain constant across cohorts, and (3) the pension tax rate should remain constant across cohorts. Combining these principles results in a simple condition that an intergenerationally equitable normal pension age must meet. The ratio of person-years lived from the normal pension age onward to the number of person-years lived from the age of labor market entry onward must be constant. In life table notation $\frac{T_{p e n}}{T_{l m e}}=K$, where pen is the normal pension age, lme is the age of labor market entry, and $K$ is a constant. Different values of $K$ arise from different combinations of pension generosity and the pension tax rate.

\subsection{Example 9: Alpha-ages and normal pension ages}

The alpha-ages that hold the proportion of adult person-years lived receiving a public pension constant at the level observed at age 65 in 2013 in Germany are shown in Table 7 for selected European countries for the years 2013, 2020, 2030, 2040, and 2050. Using a single country as a standard allows us to see what an intergenerationally equitable pension age would be if the ratio of person-years with a pension to total adult person-years was the same in all countries. In 2050, if the proportion of adult person-years spent with a pension are projected to be the same as they were for 65-year-olds in Germany in 2013, the normal pension age would have to be around 71 in France, 69 in the UK, 67 in Latvia, 66 in Bulgaria, 64 in the Russian Federation, and almost 70 in Germany itself.

Under current legislation, the normal pension age is on track to rise to 67 by 2029 in Germany, and to around 69 in the UK in the 2040s. These ages are very close 
Example 9:

Alpha-ages as normal pension ages - Table 7 (German 2013 basis)

$\alpha=C_{s}^{-1}\left(C_{r}(a)\right)$

\begin{tabular}{ll}
\hline Characteristic $(C())$ & Proportion of adult person-years lived after age $a\left(T_{\boldsymbol{a}} / \boldsymbol{T}_{\mathbf{2 0}}\right)$ \\
\hline $\begin{array}{l}\text { Constant } \\
\text { Parameters }\end{array}$ & $\begin{array}{l}\boldsymbol{a} \text { and } \boldsymbol{r} \\
\boldsymbol{a} \text { is age } 65, \\
\boldsymbol{r} \text { is the characteristic schedule for Germans in } 2013 \\
\text { (both sexes combined) }\end{array}$ \\
Variable & $\boldsymbol{s}$ \\
Parameters & $s$ is a set of similar characteristic schedules in selected \\
& $\begin{array}{l}\text { European countries in the years 2013, 2020, 2040, } \\
\text { and 2050. }\end{array}$ \\
\hline
\end{tabular}

Table 7:

Intergenerationally equitable normal pension ages

\begin{tabular}{llllll}
\hline $\begin{array}{l}\text { German basis } \\
\text { Country }\end{array}$ & $\mathbf{2 0 1 3}$ & $\mathbf{2 0 2 0}$ & $\mathbf{2 0 3 0}$ & $\mathbf{2 0 4 0}$ & $\mathbf{2 0 5 0}$ \\
\hline Bulgaria & 61.03 & 61.51 & 62.74 & 63.96 & 65.25 \\
France & 66.40 & 67.26 & 68.60 & 69.81 & 71.08 \\
Georgia & 61.44 & 62.13 & 63.36 & 64.59 & 65.85 \\
Germany & 65.00 & 65.91 & 67.26 & 68.51 & 69.80 \\
Greece & 64.95 & 66.02 & 67.39 & 68.65 & 69.95 \\
Ireland & 65.06 & 65.68 & 66.84 & 68.04 & 69.26 \\
Italy & 66.09 & 66.70 & 67.97 & 69.26 & 70.53 \\
Latvia & 61.09 & 61.93 & 63.27 & 64.62 & 65.90 \\
Russian Federation & 59.43 & 59.89 & 61.16 & 62.34 & 63.53 \\
Serbia & 61.05 & 61.81 & 63.05 & 64.28 & 65.54 \\
Slovakia & 62.05 & 62.87 & 64.21 & 65.50 & 66.81 \\
Spain & 65.92 & 66.42 & 67.76 & 69.03 & 70.31 \\
Sweden & 65.43 & 66.10 & 67.32 & 68.55 & 69.81 \\
United Kingdom & 65.23 & 65.86 & 67.13 & 68.33 & 69.56 \\
\hline
\end{tabular}

Note: The standard schedule, $s$, is for Germany in 2013, where the normal pension age is set equal to 65 . Source: Authors' calculations, see Sanderson and Scherbov (2015).

to the figures in Table 7. A more complete discussion of the relationship between the planned and the forecasted alpha-age-based normal pension ages can be found in Sanderson and Scherbov (2015). That paper also includes a discussion of the 
relationship between the alpha-age-based normal pension ages and the pension ages in the notional defined contribution pension plans.

Instead of legislating incremental increases in normal pension ages in piecemeal fashion, it would be simpler to adopt a policy based on alpha-ages. An alphaage-based pension age policy would have three important advantages. First, while future increases in life expectancy are uncertain. An alpha-age based policy would automatically adjust for changes in life expectancy. Second, as countries age it could become increasingly difficult to enact pension age changes that are consistent with intergenerational equity. A pension age policy based on alpha-ages would make those changes without repeated contentious political debates. Third, and perhaps most importantly, alpha-age based pension ages are intergenerationally equitable. The rationale for changing normal pension ages should not be that the government is running out of money, but rather that normal pension ages should be set on the basis of fairness.

\section{Related ages}

\subsection{Thanatological age}

The idea of thanatological age was introduced in Brouard (1986), and more recently there has been increased interest in the concept because of its relationship to health care costs (Miller 2001; Lubitz et al. 2003; Yang, Norton and Stearns 2003; Payne et al. 2007). Whereas chronological age is the exact number of years a person has already lived, thanatological age is the exact number of years a person has left to live. From conventional life tables, it is possible to create both thanatological life tables and thanatological characteristic schedules. One possible thanatological characteristic schedule would relate thanatological age and the average age of people who had specific numbers of years left to live. One interesting use of a thanatological life table would be to look at the proportion of the population who had five or fewer years of remaining life.

Up to this point, we have interpreted $C_{r}(a)$ as the relationship between a characteristic and chronological age in characteristic schedule $r$. It is possible to use the same formulation with thanatological age instead of chronological age. For clarity, we express the relationship between a characteristic and thanatological age as $D_{r}(b)$, where $b$ is a thanatological age.

Alpha-ages are derived from the equation:

$$
\alpha=C_{s}^{-1}\left(C_{r}(a)\right) .
$$


Beta-ages are the analogous numbers based on thanatological ages rather than chronological ages.

$$
\beta=D_{s}^{-1}\left(D_{r}(b)\right) .
$$

Riffe et al. (2017) showed how thanatological age and prospective age can be used together to study how populations age.

\subsection{Anticipated longevity}

Many surveys of older populations (such as HRS, SHARE, ELSA) include questions in which participants are asked to anticipate their longevity. Responses to these questions have been used to calculate anticipated life expectancy. Anticipated life expectancy is a characteristic that can be analyzed using alpha-ages. This has been done in Aktas and Sanderson (2015), in which estimates from anticipated life tables were transformed into anticipatory ages. Palloni and Novak (2017) showed that subjective life tables and observed life tables are consistent with each other.

\section{Technical considerations}

Computing alpha-ages involves inverting continuous and monotonic characteristic schedules. In practice, characteristic schedules are often not continuous. For example, life tables provide life expectancies for people at their $60^{\text {th }}$ and $61^{\text {st }}$ birthdays, but not when they are 60 years and 6 months old. This problem is easily solved by interpolating the unobserved values of characteristics between chronological ages. Characteristic schedules also need not always be monotonic. In this were the case, we would only study those portions of the schedules the are monotonic. In this paper, the problem of non-monotonicity never arose.

All of the forecasts of aging in this paper are based on forecasts of life tables produced either for the European Demographic Datasheet (VID 2014) or by the United Nations (2013b). The methodologies for forecasting life tables are well understood. Life expectancies are projected to increase slightly faster in the European Demographic Datasheet than in the United Nations estimates. Life table forecasts can also be used to compute more complex forecasts based on the Sullivan method (Sullivan 1971). In that method, age-specific characteristics, such as being without a severe disability, are applied to life tables. This approach can be used to forecast healthy life expectancies, assuming that the age-specific prevalence of the characteristic does not change.

Characteristic schedules are uncertain. Especially in cases in which the degree of uncertainty is not trivial, it is important to compute it precisely, and to include it in the analysis. We do this in the discussion of alpha-ages based on hand grip strength (see Example 8). 


\section{Concluding discussion}

There is a common narrative that population aging will lead to serious fiscal challenges. This argument is based on the observation that the ratio of people aged 65 and older to people aged 15 to 64 is rising dramatically in many countries. It is generally expected that the older group will be dependent on the younger group for their pensions and health care, and that the resulting increases in taxes on the young to finance those expenditures will reduce their incentives to work and save, thereby reducing economic growth.

Fortunately, this narrative is largely wrong. Normal pension ages are in the process of changing. A number of the countries that once had a normal pension age of 65 have since raised this age. In many OECD countries, normal pension ages are scheduled to increase to 67 and even higher in the next few decades. In addition to changes in normal pension ages, there have been numerous changes in pension eligibility rules, which have an effect similar to that of raising the normal pension age (OECD 2014, 2013, 2011). Analyzing the fiscal problems of population aging based on the assumption that the normal pension ages will remain fixed at 65 is incorrect and misleading.

A similar sort of problem arises with the interpretation of age 65 as the age at which people begin to have significantly higher medical expenses. First, health care expenditures are concentrated in the last few years of life (Miller 2001; Lubitz et al. 2003; Yang, Norton and Stearns 2003; Payne et al. 2007). With increases in life expectancy, those last few years of life are gradually postponed. Ignoring increases in life expectancy produces estimates of health care costs that rise too rapidly. Second, life expectancy without severe disabilities is rising with increases in life expectancy, and the onset of severe disabilities is also being postponed (Sanderson and Scherbov 2010). Ignoring this trend also produces an upward bias in estimates of the burden that the elderly will impose on younger people.

Since the narrative of the rapid increase in the burdens associated with population aging is so transparently biased, it is interesting to ask why it is so common. One reason, we suspect, is that policy-makers, journalists, and others interested in population aging have not had easy access to measures of population aging that take into account the changing characteristics of the population. In this paper and in earlier ones, we have provided easy-to-use measures that offer a different and more realistic narrative.

However, alpha-ages provide more than just better aggregate measures of population aging; they provide a methodology for translating characteristics that are measured in very different units into a common metric. This unification process allows for the construction of composite measures of population that are easy to understand and interpret. In other words, alpha-ages provide us with the ability to study the multidimensional phenomenon of population aging using appropriate multidimensional indices. Furthermore, as an example of the applicability of this approach to public policy, we have also shown how alpha-ages can be used to produce an analytically-based, intergenerationally equitable normal pension age. 
Population aging in the $21^{\text {st }}$ century cannot be adequately studied using tools that do not take into account the changing characteristics of the population. The older tools were developed in an era when the relevant characteristics of people were changing relatively slowly. As this is no longer the case, the scientific study of population aging and policy formulation should no longer be based on those tools. Using alpha-ages, it is now possible to study $21^{\text {st }}$ century population aging with appropriate $21^{\text {st }}$ century tools.

\section{Acknowledgements}

This work was partly supported by the European Research Council under the European Union's Seventh Framework Programme (FP7/2007-2013) / ERC under Grant ERC2012-AdG 323947-Re-Ageing.

\section{References}

Aktas, Arda and Warren C. Sanderson 2015. A forward looking age based on longevity expectations. IIASA Interim Report IR-15-016. Laxenburg, Austria: International Institute for Applied Systems Analysis (IIASA). http://pure.iiasa.ac.at/11673/1/IR-15-016.pdf.

Al Snih, Soham, Kyriakos S. Markides, Kenneth J. Ottenbacher and Mukaila A. Raji 2004. Hand grip strength and incident ADL disability in elderly Mexican Americans over a seven-year period. Aging Clinical and Experimental Research 16 (6): 481-86. doi:10.1007/BF03327406.

Al Snih, Soham, Kyriakos S. Markides, Laura Ray, Glenn V. Ostir and James S. Goodwin 2002. Handgrip strength and mortality in older Mexican Americans. Journal of the American Geriatrics Society 50 (7): 1250-1256. doi:10.1046/j.1532-5415.2002.50312.x.

Ambrasat, Jens, Jürgen Schupp and Gert G. Wagner 2011. Comparing the predictive power of subjective and objective health indicators: Changes in hand grip strength and overall satisfaction with life as predictors of mortality. SOEPpapers on Multidisciplinary Panel Data Research 398.

Brouard, Nicolas 1986. Structure et dynamique des populations. La pyramide des années à vivre, aspects nationaux et exemples régionaux. Espace, Populations, Sociétés 4(2): 157-68. doi:10.3406/espos.1986.1120.

Christensen, Kaare, Michael Davidsen, Knud Juel, Laust Mortensen, Roland Rau and James W. Vaupel 2010. The divergent life-expectancy trends in Denmark and Sweden-and some potential explanations. http://www.ncbi.nlm.nih.gov/books/NBK62583/.

Demuru, Alberto 2017. Controlling prospective age for health status: How to rejuvenate the population by improving health. Vienna Yearbook of Population Research 2016 (forthcoming).

Emelyanova, Anastasia and Arja Rautio 2017. Population ageing dynamics in the North Atlantic region of the Arctic. Vienna Yearbook of Population Research 2016 (forthcoming). 
EurOhex 2015. Ja:EHLEIS Information System. Accessed June 16. http://maryland.mri. cnrs.fr/ehleis/IS/index.php?controller=healthExpectancies/NationalHealths\&action= displayDataForSPH.

Eurostat 2013. Life expectancy by age, sex, and educational attainment (ISCED 1997). European Union. http://appsso.eurostat.ec.europa.eu/nui/show.do?dataset=demo_ mlexpecedu\&lang=en.

Flynn, James R. 1987. Massive IQ gains in 14 nations: What IQ tests really measure. Psychological Bulletin 101(2): 171-91. doi:10.1037/0033-2909.101.2.171.

Habibi, Ehsanollah, Meghdad Kazemi, Habibollah Dehghan, Behzad Mahaki and Akbar Hassanzadeh 2013. Hand grip and pinch strength: Effects of workload, hand dominance, age, and body mass index. Pakistan Journal of Medical Sciences 29 (1, Suppl). doi:10.12669/pjms.291(Suppl).3535.

Innes, Ev 1999. Handgrip strength testing: A review of the literature. Australian Occupational Therapy Journal 46 (3): 120-140. doi:10.1046/j.1440-1630.1999.00182.x.

Leong, Darryl P, Koon K Teo, Sumathy Rangarajan, Patricio Lopez-Jaramillo, Alvaro Avezum Jr, Andres Orlandini, Pamela Seron, et al. 2015. Prognostic value of grip strength: Findings from the prospective urban rural epidemiology (PURE) study. The Lancet. doi:10.1016/S0140-6736(14)62000-6.

Levine, Morgan E. and Eileen M. Crimmins 2014. A Comparison of methods for assessing mortality risk. American Journal of Human Biology 26(6): 768-76. doi:10.1002/ajhb.22595.

Lubitz, James, Liming Cai, Ellen Kramarow and Harold Lentzner 2003. Health, life expectancy, and health care spending among the elderly. New England Journal of Medicine 349(11): 1048-55. doi:10.1056/NEJMsa020614.

Lutz, Wolfgang, Warren C. Sanderson and Sergei Scherbov 2008. The coming acceleration of global population ageing. Nature 451(7179): 716-19. doi:10.1038/nature06516.

Miller, Tim 2001. Increasing longevity and medicare expenditures. Demography 38(2): 215-26. doi:10.1353/dem.2001.0018.

OECD 2011. Pensions at a glance 2011: Retirement-income systems in OECD and G2O countries. Paris: OECD. http://www.oecd.org/berlin/publikationen/ pensionsataglance2011 retirement-incomesystemsinoecdundg20countries.htm.

OECD 2013. Pensions at a glance 2013: Retirement-income systems in OECD and G20 countries. Paris: OECD. http://www.oecd.org/pensions/pensionsataglance.htm.

OECD 2014. OECD pensions outlook 2014. Paris: OECD Publishing.

Palloni, Alberto and Beatriz Novak 2017. Subjective survival expectations and observed survival: How consistent are they? Vienna Yearbook of Population Research 2016 (forthcoming).

Payne, Greg, Audrey Laporte, Raisa Deber and Peter C. Coyte 2007. Counting backward to health care's future: Using time-to-death modeling to identify changes in end-of-life morbidity and the impact of aging on health care expenditures. Milbank Quarterly 85(2): 213-57. doi:10.1111/j.1468-0009.2007.00485.x.

Rehkopf, David, Luis Rosero-Bixby and William Dow 2017. A cross-national comparison of twelve biomarkers finds no universal biomarkers of aging. Vienna Yearbook of Population Research 2016 (forthcoming). 
Riffe, Tim, Phil H. Chung, Jeroen Spijker and John MacInnes 2017. Time-to-death patterns in markers of age and dependency. Vienna Yearbook of Population Research 2016 (forthcoming).

Ryder, Norman B. 1975. Notes on stationary populations. Population Index 41(1): 3-28. doi:10.2307/2734140.

Sanderson, Warren C. and Sergei Scherbov 2005. Average remaining lifetimes can increase as human populations age. Nature 435(7043): 811-13. doi:10.1038/nature03593.

Sanderson, Warren C. and Sergei Scherbov 2007. A new perspective on population aging. Demographic Research 16 (January): 27-57. doi:10.4054/DemRes.2007.16.2.

Sanderson, Warren C. and Sergei Scherbov 2008a. Conventional and prospective measures of population aging, 1995, 2005, 2025, 2045. Population Reference Bureau. http://www.prb.org/excel08/age-ageing_table.xls.

Sanderson, Warren C. and Sergei Scherbov 2008b. Rethinking age and aging. Population Bulletin 63 4. Washington, D.C.: Population Reference Bureau. http://www.prb.org/pdf08/63.4aging.pdf.

Sanderson, Warren C. and Sergei Scherbov 2010. Remeasuring aging. Science 329 (5997): 1287-88. doi:10.1126/science.1193647.

Sanderson, Warren C. and Sergei Scherbov 2013. The characteristics approach to the measurement of population aging. Population and Development Review 39(4): 673-85. doi:10.1111/j.1728-4457.2013.00633.x.

Sanderson, Warren C. and Sergei Scherbov 2014. Measuring the speed of aging across population subgroups. PLOS ONE 9(5): e96289. doi:10.1371/journal.pone.0096289.

Sanderson, W. C. and S. Scherbov 2015. An easily understood and intergenerationally equitable normal pension age. In The future of welfare in a global Europe, ed. B. Marin, 193-220. Farnham, UK: Ashgate Publishing.

Sanderson, Warren C. and Sergei Scherbov 2016. A new perspective on patterns of aging in Europe by education and gender. Journal of Population Ageing 9(3): 207-225. doi:10.1007/s12062-015-9125-z.

Scherbov, Sergei and Warren C. Sanderson 2014. Prospective measures of population aging: Version 1.0, June, 2014. www.reaging.org/indicators.

Schneeweis, Nicole, Vegard Skirbekk and Rudolf Winter-Ebmer 2014. Does education improve cognitive performance four decades after school completion? Demography 51(2): 619-43. doi:10.1007/s13524-014-0281-1.

Skirbekk, Vegard, Elke Loichinger and Daniela Weber 2012. Variation in cognitive functioning as a refined approach to comparing aging across countries. Proceedings of the National Academy of Sciences 109(3): 770-74. doi:10.1073/pnas.1112173109.

Stoet, Gijsbert and David C. Geary 2013. Sex Differences in mathematics and reading achievement are inversely related: Within- and across-nation assessment of 10 years of PISA data. PLoS ONE 8(3): e57988. doi:10.1371/journal.pone.0057988.

Stojilkovic Gnjatovic, Jelena 2017. Some characteristics of population ageing using prospective approach: Serbia as case study. Vienna Yearbook of Population Research 2016 (forthcoming).

Sullivan, Daniel F. 1971. A single index of mortality and morbidity. HSMHA Health Reports 86(4): 347-54. doi:10.2307/4594169. 
United Nations 2013a. World population ageing 2013. ST/ESA/SER.A/348. New York, USA: Department of Economic and Social Affairs, Population Division. http://www.un.org/en/development/desa/population/publications/pdf/ageing/ WorldPopulationAgeing2013.pdf.

United Nations 2013b. World population prospects: The 2012 revision. New York, NY: Department of Economic and Social Affairs, Population Division. http://esa.un.org/wpp/Excel-Data/EXCEL_FILES/3_Mortality/WPP2012_MORT_ F13_3_LIFE_EXPECTANCY_60_FEMALE.XLS.

VID 2014. European demographic data sheet 2014. Vienna, Austria: Vienna Institute of Demography. http://www.iiasa.ac.at/web/home/research/researchPrograms/ WorldPopulation/PublicationsMediaCoverage/ModelsData/EU_data_sheet_2014.pdf.

Weber, Daniela, Vegard Skirbekk, Inga Freund and Agneta Herlitz 2014. The changing face of cognitive gender differences in Europe. Proceedings of the National Academy of Sciences 111(32): 11673-78. doi:10.1073/pnas.1319538111.

Yang, Zhou, Edward C. Norton and Sally C. Stearns 2003. Longevity and health care expenditures the real reasons older people spend more. The Journals of Gerontology Series B: Psychological Sciences and Social Sciences 58(1): S2-10. doi:10.1093/geronb/58.1.S2. 
